\title{
The effects of petoelum retention and migration within the Triassic Chang 7 Member in the Ordos Basin in China
}

\author{
YANYAN CHEN, SENHU LIN, BIN BAI, SHIZHEN TAO
}

The Research Institute of Petroleum Exploration and

Development, PetroChina, Beijing, 100083

The Ordos Basin is one of the most petroliferous basin in China. The newly discovered Qingcheng Oilfield in the Ordos Basin, mainly sourced by the organic-rich Chang 7 Member of the Upper Triassic Yanchang Formation, was reported to hold more than one billion tons of tight oil reserves, inspiring renewed interest in the studies of unconventional resources in China.

Our understanding of petroleum retention, migration, and expulsion from the Chang 7 Member, which are particularly vital for shale oil exploration and development, is still limited. Therefore, in this study, the effects of petroleum retetnion within and expulsion from five intervals within the organicrich source rock, have been demostrated by deciphering a large suite of petrologic, orgnaic petrographic, and organic geochemical analyses on 106 core samples.

Organic properties and lithological heterogeneities control the amount and chemical composition of retained petroleum. Enrichment of aliphatic hydrocarbons in the silty, organic-lean intervals versus enrichment of aromatic fluids in the clayey, organic-rich units are probably caused by compositional fractionation occurred during primary and short-distance secondary migration. Migration of excess petroleum from organic-rich units to those organic-lean counterparts was further corroborated by the negative expulsion efficiencies calculated using a mass-balance model in the organic-lean intervals. Capillary pressure difference induced by the contrast in pore throat size of the clayey, organic-rich versus the silty, organic-lean intervals is postulated to be the major drive for the migration.

A significant implication of this study is that the hydrocarbons in the first and fourth intervals constitute potential petroleum exploitation targets, given (i) improved oil quality caused by enriched aliphatic compounds, (ii) lower sorption affinities exerted by kerogen structure, (iii) relatively high degree of brittleness in these two intervals. Despite its high content of retained hydrocarbons, organic-rich fifth interval is not the best target, mainly due to the high sorption affinities of organic matter structure thereby causing low oil mobility and producibility. 